\title{
DNA copy number analysis of Grade II-III and Grade IV gliomas reveals differences in molecular ontogeny including chromothripsis associated with IDH mutation status
}

Adam Cohen ${ }^{1 *}$, Mariko Sato ${ }^{2}$, Kenneth Aldape ${ }^{3}$, Clinton C. Mason ${ }^{1}$, Kristin Alfaro-Munoz ${ }^{3}$, Lindsey Heathcock ${ }^{3}$, Sarah T. South ${ }^{4,6}$, Lisa M. Abegglen', Joshua D. Schiffman ${ }^{1,5+}$ and Howard Colman ${ }^{1+}$

\begin{abstract}
Introduction: Isocitrate dehydrogenase $(I D H)$ mutation status and grade define subgroups of diffuse gliomas differing based on age, tumor location, presentation, and prognosis. While some biologic differences between IDH mutated $\left(I D H^{\text {mut }}\right)$ and wild-type $\left(I D H^{\text {wt }}\right)$ gliomas are clear, the distinct alterations associated with progression of the two subtypes to glioblastoma (GBM, Grade IV) have not been well described. We analyzed copy number alterations (CNAs) across grades (Grade II-III and GBM) in both IDH $H^{\text {mut }}$ and IDH $H^{\text {wt }}$ infiltrating gliomas using molecular inversion probe arrays.

Results: Ninety four patient samples were divided into four groups: Grade II-III IDH ${ }^{\text {wt }}(n=17)$, Grade II-III IDH ${ }^{\text {mut }}$ ( $n$ $=28), \mathrm{GBM} I D H^{\text {wt }}(n=25)$, and GBM IDH ${ }^{\text {mut }}(n=24)$. We validated prior observations that IDH ${ }^{\text {wt }} \mathrm{GBM}$ have a high frequency of chromosome 7 gain (including EGFR) and chromosome 10 loss (including PTEN) compared with $I D H^{\text {mut }} \mathrm{GBM}$. Hierarchical clustering of IDH $H^{\text {mut }}$ gliomas demonstrated distinct CNA patterns distinguishing lower grade gliomas versus GBM. However, similar hierarchical clustering of IDH ${ }^{\text {wt }}$ gliomas demonstrated no CNA distinction between lower grade glioma and GBM. Functional analyses showed that IDH ${ }^{\text {wt }}$ gliomas had more chromosome gains in regions containing receptor tyrosine kinase pathways. In contrast, IDH ${ }^{\text {mut }}$ gliomas more commonly demonstrated amplification of cyclins and cyclin dependent kinase genes. One of the most common alterations associated with transformation of lower grade to GBM IDH ${ }^{\text {mut }}$ gliomas was the loss of chromosomal regions surrounding PTEN. IDH ${ }^{\text {mut }}$ GBM tumors demonstrated significantly higher levels of overall CNAs compared to lower grade IDH ${ }^{\text {mut }}$ tumors and all grades of IDH $H^{\text {wt }}$ tumors, and IDH $H^{\text {mut }}$ GBMs also demonstrated significant increase in incidence of chromothripsis.

Conclusions: Taken together, these analyses demonstrate distinct molecular ontogeny between IDH $H^{\text {wt }}$ and IDH $H^{\text {mut }}$ gliomas. Our data also support the novel findings that malignant progression of ID $H^{\text {mut }}$ gliomas to GBM involves increased genomic instability and genomic catastrophe, while IDH $H^{\text {wt }}$ lower grade tumors are virtually identical to GBMs at the level of DNA copy number alterations.
\end{abstract}

Keywords: Isocitrate dehydrogenase, Glioma, Glioblastoma, Copy number alterations, Chromothripsis

\footnotetext{
* Correspondence: adam.cohen@hci.utah.edu

${ }^{\dagger}$ Equal contributors

'Huntsman Cancer Institute, University of Utah, 2000 Circle of Hope, Salt Lake

City, UT 84112, USA

Full list of author information is available at the end of the article
} 


\section{Introduction}

Gliomas are the most frequent primary malignant brain tumors with an annual incidence of approximately 20,000 cases in the United States [9]. Glioblastoma (GBM) is the most common glioma and remains nearly uniformly fatal, with a median survival under 16 months in aggressively treated patients [17]. While these tumors are currently diagnosed by histopathology alone and generally treated based on histology and grade, recent findings identifying distinct molecular subgroups within these tumor types strongly suggest that improving treatments and patient survival will require detailed understanding of the biological and clinical differences between these subgroups.

Histopathologically, diffuse gliomas are categorized according to the WHO by histology (Astrocytoma, Oligodendroglioma, or Oligoastrocytoma) and grade [lower grade (grade II/III) versus glioblastoma (GBM, grade IV)]. Clinically, GBMs have been classified as primary or secondary on the basis of clinical presentation [34]. Secondary GBMs, which are more common in young adults, display evidence of progression from a lowergrade tumor, whereas primary GBMs, which are more common in older adults, present as advanced cancers at diagnosis [28]. Recently, large scale efforts have been made to identify the major genetic and epigenetic alterations and to define important molecular subtypes in GBM and lower grade gliomas [30, 43, 41]. The strongest prognostic factor for all glioma histologies is mutation in one of the isocitrate dehydrogenase genes (IDH1 or IDH2) [48], and mutation of these genes is seen at higher frequencies in lower grade gliomas and secondary GBMs.

Chromosome abnormalities in gliomas have been associated with various subgroups. A summary of over 400 GBMs showed gains in EGFR (7p12) in $30 \%$, GLI/ CDK4/MDM2 (12q13-14) in $13 \%$, PIK3C2B/MDM4 (1q32) in $8 \%$, PDGFRA (4q12) in $8 \%$, and $M E T$ (7q31) in $4 \%$ with deletions in $C D K N 2 A / 2 B$ (9p21) in $47 \%$, PTEN (10q23) in $10 \%$, and RB1 (13q14) in $6 \%$ [31]. Primary GBMs commonly have gains in chromosome 7 and 19 and loss of chromosome 10 [31, 22, 25, 26, 46, 2]. Secondary or $I D H$ mutated glioblastomas are less likely to have the above alterations and more likely to have gains in 8q and 10q accompanying simpler karyotypes [27, 22, 20, 25]. Grade II astrocytomas have been less well studied, with gains in $7 \mathrm{q}$ described in two studies $[7,12]$, and other alterations not replicated [7, 12, 46]. Although some groups have found worse prognosis in GBMs with either EGFR or chromosome 7 amplifications $[15,6,26,13]$, others, including the largest study $(n=532)$, found no association with outcome [14, 46, 13]. One reason for this inconsistency may be confounding due to the association of EGFR amplification with other known prognostic factors, such as age, G-CIMP status, or IDH mutation status [8, 3, 27, 22, 25, 20]. Only one study has looked at the prognosis of copy nuber alterations (CNAs) within subgroups defined by IDH status, suggesting that chromosome $7 \mathrm{p}$ gain and TP53 loss are prognostic in grade III gliomas with IDH mutation [37].

Gliomas have chromosomal instability, with a propensity for recurring patterns of CNAs [21,36]. Although multiple mechanisms may be responsible for CNAs in gliomas, chromothripsis is a recently described form of localized CNA due to chromosomal catastrophe that may occur commonly in gliomas [18, 23]. Chromothripsis, which literally means "chromosome shattering," can be identified from CNA technologies such as SNP microarrays. The association of chromothripsis with clinical factors and prognosis in gliomas has not been explored to date.

The purpose of this study is to determine CNAs within glioma subgroups defined by grade and IDH status. We deliberately chose to maximize the percent of $I D H^{\text {mut }}$ grade IV gliomas and $I D H^{\text {wt }}$ lower grade gliomas, as these are rare in most other studies. In addition, we examine prognostic CNAs within each glioma subgroup and chromothripsis as a function of grade and IDH status.

\section{Materials and methods}

\section{Samples and nucleic acid extraction}

We analyzed formalin-fixed, paraffin-embedded (FFPE) glioma specimens from 94 patients from M.D. Anderson Cancer Center (Houston, TX) and 20 autopsied normal brains (controls) from Huntsman Cancer Institute, University of Utah (Salt Lake City, UT). IRB approval was obtained from each institution. IDH mutation status was confirmed using direct sequencing [42]. Gliomas were categorized by a single neuropathologist (KA) as either high grade (GBM) or lower grade (grade II or III). DNA was isolated using the Recoverall Total Nucleic Acid Isolation kit (AM1975, Applied Biosystems/Ambion, Austin, TX) and quantified with a high sensitivity, double strand specific, nucleic acid, fluorescent stain (PicoGreen, P7589, Invitrogen, Carlsbad, CA).

\section{Copy number analysis}

The DNA was plated in a 96-well plate with concentration goal of $7.5 \mathrm{ng} / \mathrm{ul}$ in a total volume of $40 \mathrm{ul}(300 \mathrm{ng}$ total). The completed plates were sent to the Affymetrix Research Services Laboratory at Santa Clara, CA, and the OncoScan ${ }^{\text {Tw }}$ FFPE Express MIP assay was run as previously described $[45,35,44]$. The raw MIP data from the completed assay was loaded into Nexus Copy Number (BioDiscovery, Inc., El Segundo, CA). Stringency cutoffs for probe performance included call rates $\geq 90 \%$ and 
standard deviations $\leq 0.3$. BioDiscovery's SNP-Rank Segmentation algorithm with Quadratic Wave Correction, a statistically based algorithm similar to Circular Binary Segmentation (CBS), was used to make copy number and loss of heterozygosity (LOH) calls [29]. The significance threshold for segmentation was set at 5.0E-7 and required a minimum of five probes per segment. CNA thresholds were based on sample mosaicism, and set at 0.4 and -0.4 units of copy number from diploidy. High gain and homozygous loss were denoted by 1.2 and -1.2 units of copy number from diploidy. Genes were assigned to regions using the NCBI36/hg18 genome assembly on the UCSC genome browser. Gene gain was considered based on the copy number for that gene, without regard for entire chromosome gain or loss.

\section{Statistics}

In order to assess the significance of the genomic alterations, Genomic Identification of Significant Targets in Cancer (GISTIC) was used to define deletions and gains and to calculate the $q$-value [40,39], taking into account the frequency, amplitude and focality of the observed gains and deletions. CNAs with $q<0.25$ were considered significant. Univariate and multivariate Cox proportional hazards models were fit to the data using Cox regression in SAS 9.3. Multivariable models were built using backward stepwise regression from a model including all variables with $p<0.1$ in univariate analysis and maintaining variables with $p<0.05$ in the multivariate analysis. Hazard ratios and $p$-values from the associated log-rank tests were reported. $P$-values for copy number alterations were adjusted using the Benjamini \& Hochberg step-up false discovery rate (FDR) controlling procedure [1]. The adjustment was done separately for each analysis. Hierarchical clustering was done using complete linkage disregarding the sex chromosomes. We also used gene ontology analysis to identify altered pathways within and between glioma subgroups using the ToppGene system [5]. We disregarded pathways determined by genes grouped together on a single chromosome and, thus, affected as a single group by large CNAs. The heatmap in Fig. 3d was generated using the HeatMapImage module from Genepattern using the default color scheme [33]. Fisher's exact test was used for contingency table analyses.

\section{Results}

\section{Population}

The cohort included a total of 94 diffuse gliomas: 17 Grade II-III IDH1 wild type (IDH1 ${ }^{\text {wt }}$ ), 28 Grade II-III IDH1 mutant (IDH1 ${ }^{\text {mut }}$ ), 25 Grade IV (glioblastoma, GBM) IDH1 $1^{\text {wt }}$, and 24 Grade IV IDH1 ${ }^{\text {mut }}$. Thirty-four patients (36\%) were female, and sixty (64\%) were male. The median survival for the population as a whole was 112 weeks, comparable to previously reported survival data. As expected, tumor grade $(\mathrm{HR}=2.2, p=0.003)$ and $I D H$ status $(\mathrm{HR}=26.7, p<0.0001)$ were independent predictors of survival (Fig. 1a). The median survival was 37.4 weeks for patients with $I D H^{\mathrm{wt}} \mathrm{GBM}, 65.4$ weeks for patients with $I D H^{\text {wt }}$ Grade II-III gliomas, 270.3 weeks for patients with $I D H^{\text {mut }} \mathrm{GBM}$, and 604.3 weeks for patients with $I D H^{\text {mut }}$ Grade II-III tumors (Fig. 1a). Indeed, IDH mutation status was a stronger prognostic factor than grade, as $\mathrm{IDH}^{\mathrm{wt}}$ lower grade gliomas had a worse prognosis than $\mathrm{IDH}^{\mathrm{mut}}$ grade IV gliomas, a finding previously observed in independent datasets $[48,11]$.

\section{Copy number alterations (CNAs) by subgroup}

CNAs identified as significant within each of the four clinical/molecular subgroups using GISTIC $q$-values for CNAs are shown in Fig. 1b Due to their distinct chromosomal abnormalities and clinical characteristics, the lower grade oligodendroglial tumors with $1 \mathrm{p} / 19 \mathrm{q}$ codeletion $(n=5)$ were analyzed separately (Fig. 1a,c). A complete list of GISTIC significant CNAs in each subgroup defined by IDH status and grade is given in Additional file 1: Table S1.

On a global scale, different patterns of CNA were seen in $I D H^{\mathrm{mut}}$ and $I D H^{\mathrm{wt}}$ gliomas. Within $I D H^{\mathrm{wt}}$ gliomas, the significant CNAs observed in lower grade and GBM tumors were generally very similar, including gain of entire copies of chromosome 7, loss of entire copies of chromosome 10, and focal losses at chromosome 9 around the $C D K N 2 A / C D K N 2 B$ locus. On the other hand, $I D H^{\text {mut }}$ lower grade gliomas and GBMs demonstrate distinct CNAs associated with grade (described further below). Copy number differences between $I D H^{\mathrm{wt}}$ gliomas and $I D H^{\text {mut }}$ gliomas, regardless of grade, are listed in Additional file 2: Table S2 and shown in Fig. 2a.

\section{$I D H^{\text {wt }}$ gliomas are similar regardless of grade}

To examine molecular subgroups within tumors separated by $I D H$ and $1 \mathrm{p} / 19 \mathrm{q}$ status, we used unsupervised hierarchical clustering. In $I D H^{\mathrm{wt}}$ gliomas, lower grade and grade IV gliomas clustered together in one large top level cluster (Fig. 2b), indicating that lower and high grade $I D H^{\mathrm{wt}}$ tumors share similar CNA alterations. The CNA alterations seen most frequently across all grades of $I D H^{\mathrm{wt}}$ gliomas were broad gain of chromosome 7 and loss of chromosome 10 (Arrows, Fig. 2b). This pattern of large CNAs in $I D H^{w t}$ gliomas contrasts with $I D H^{\text {mut }}$ gliomas, in which changes on chromosomes 7 and 10 were either absent or more focal around the EGFR, MGMT, and/or PTEN genes (Arrows, Fig. 2c).

Despite the similarity between $I D H^{\mathrm{wt}}$ lower grade versus grade IV gliomas on clustering analysis, there were a few chromosome areas with significant differences between the two grades (Additional file 3: Table S3 and Fig. 3a). Interestingly, there were no CNAs that were 
A

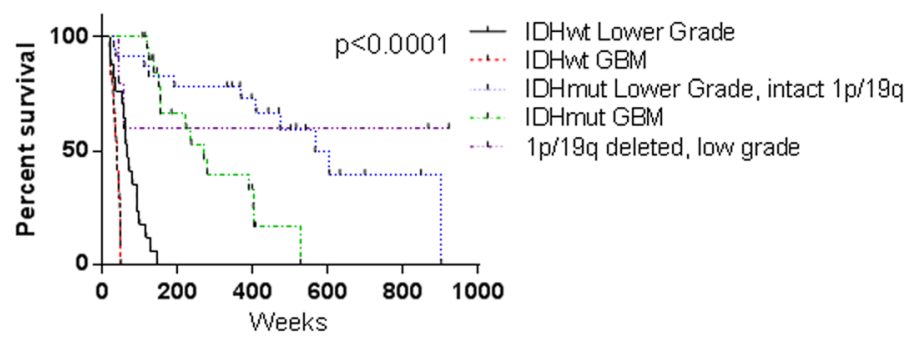

B

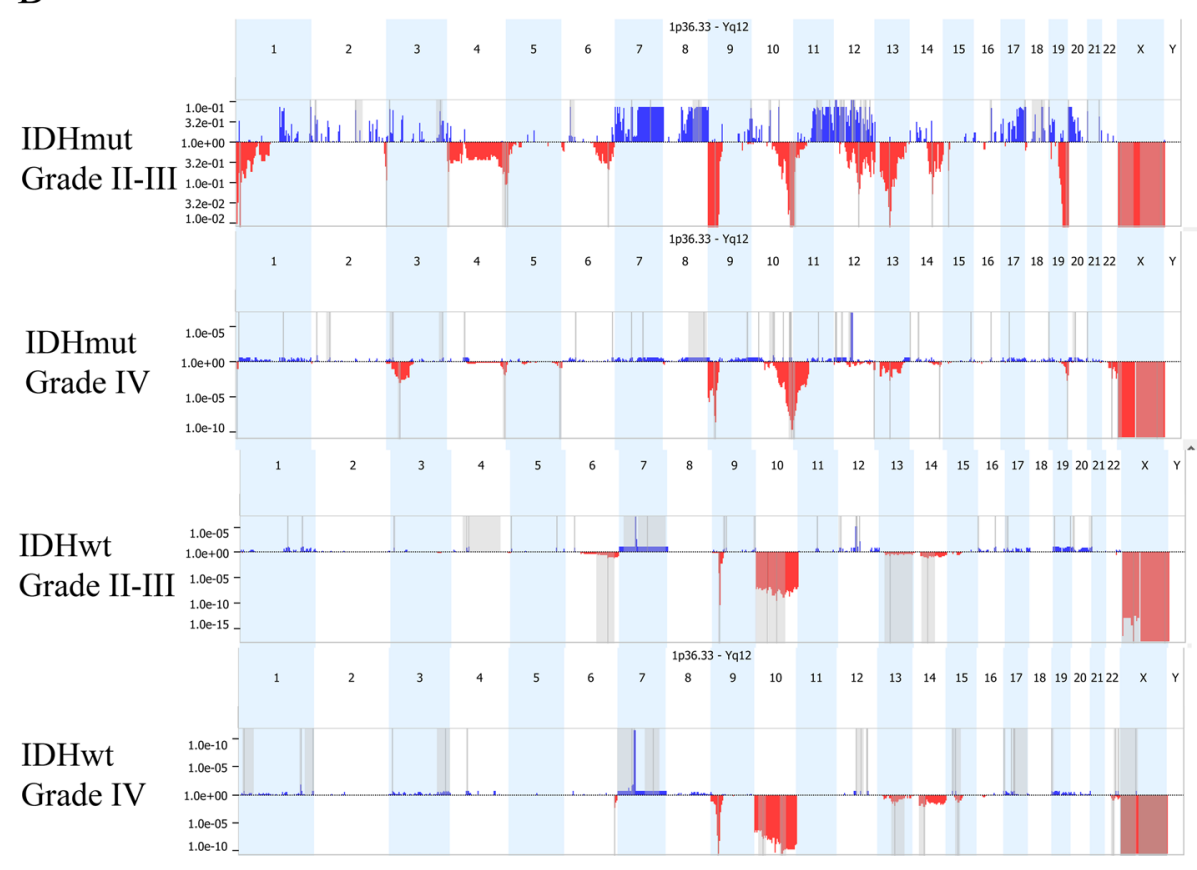

$\mathrm{C}$

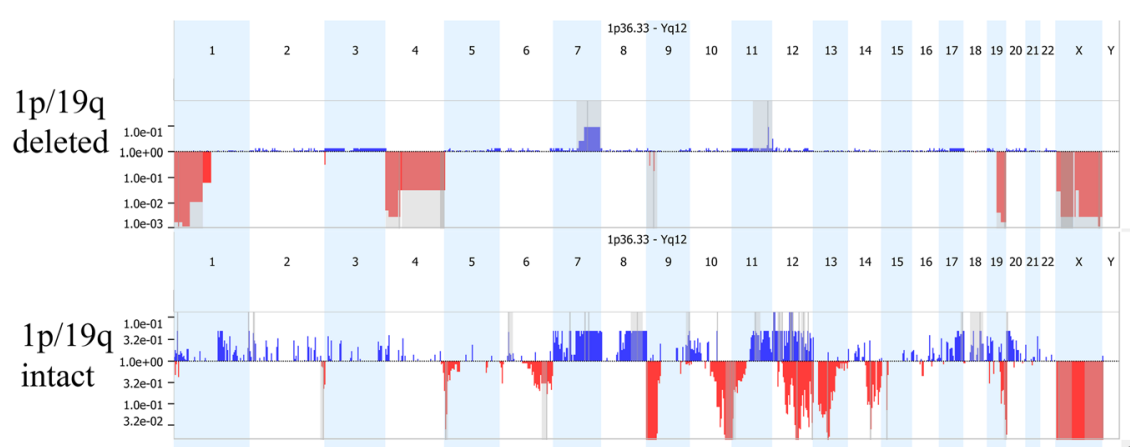

Fig. 1 a. Kaplan-Meier curves of five groups of gliomas determined by grade, IDH mutation status, and 1p/19q deletion. All 94 patients were included. $\mathbf{b}$. Chromosome maps from GISTIC analysis of four subgroups of gliomas defined by IDH status and grade. The y-axis gives GISTIC $q$-values. Red indicates deletions and blue indicates gains. c. Chromosome maps from GISTIC analysis for grade II-III IDH mutated gliomas separated by $1 \mathrm{p} / 19 \mathrm{q}$ status

more common in high grade $I D H^{\mathrm{wt}}$ gliomas than in lower grade $I D H^{\mathrm{wt}}$ gliomas. Rather, there were several chromosomal regions, which are listed in Additional file 3: Table S3, that were less likely to be gained in grade IV $\left(I D H^{\mathrm{wt}}\right)$ gliomas than in lower grade $I D H^{\mathrm{mut}}$ gliomas.
Many of these regions contain tumor suppressor genes such as TP53 or XRCC1, as well as putative protooncogenes BCL3,CDK4, and HIF3A. The fact that no CNAs were more common in high grade $I D H^{\mathrm{wt}}$ gliomas than in lower grade $I D H^{\mathrm{wt}}$ gliomas supports the concept 


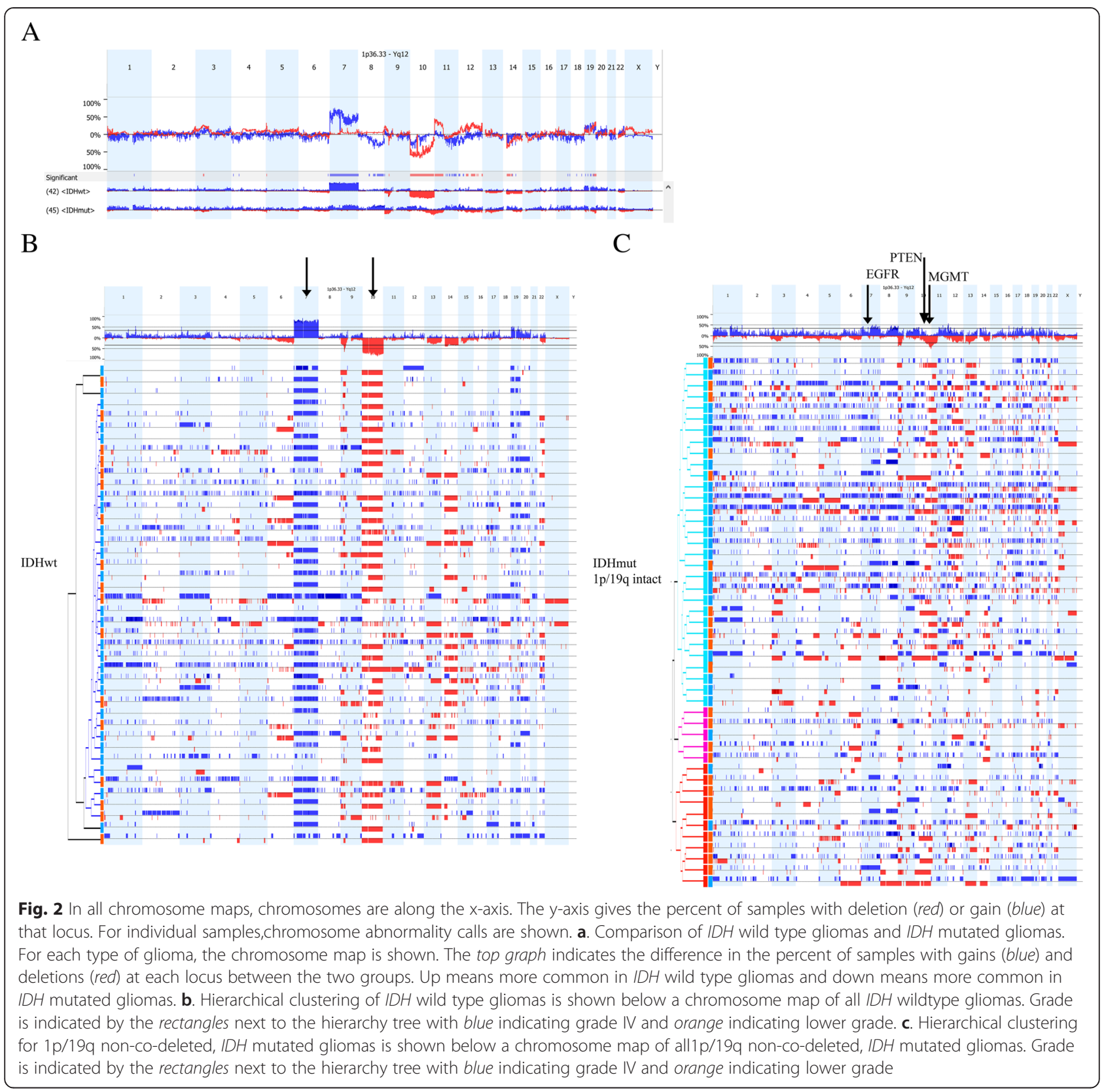

that the recurring copy number aberrations seen in $I D H^{\mathrm{wt}}$ GBM are likely to be present in grade II-III precursor tumors. Alternatively, the data are consistent with the possibility that subclones from the lower grade $I D H^{\mathrm{wt}}$ tumors can progress into grade IV gliomas (Additional file 3: Table S3 and Fig. 3a).

Using functional gene ontology analysis to identify relevant pathways associated with significant CNAs, we found that $I D H^{\mathrm{wt}}$ lower grade gliomas were enriched for alterations in pathways involving $\mathrm{RB} /$ checkpoint signaling, kinase binding, PI3K/AKT signaling, and cell cycle control. We also identified the pathways enriched in CNAs that differed between lower and high grade $I D H^{\mathrm{wt}}$ gliomas. These pathways included base excision repair, telomerase extension, nucleotide excision repair, and repair of abasic sites, suggesting a small window of sensitivity may exist to DNA damaging agents early in $I D H^{\mathrm{wt}}$ GBM development.

Progression to grade IV in IDH ${ }^{\text {mut }}$ gliomas involves losses on chromosome 10 and increased chromosome instability Among 1p/19q non-co-deleted $I D H^{\text {mut }}$ gliomas, unsupervised clustering identified two major clusters with significantly different percent of high and lower grade gliomas in each cluster $(p=0.018)$. One large cluster included $83 \%$ (20) of the $I D H^{\text {mut }}$ GBMs but only $48 \%$ (11) of the 


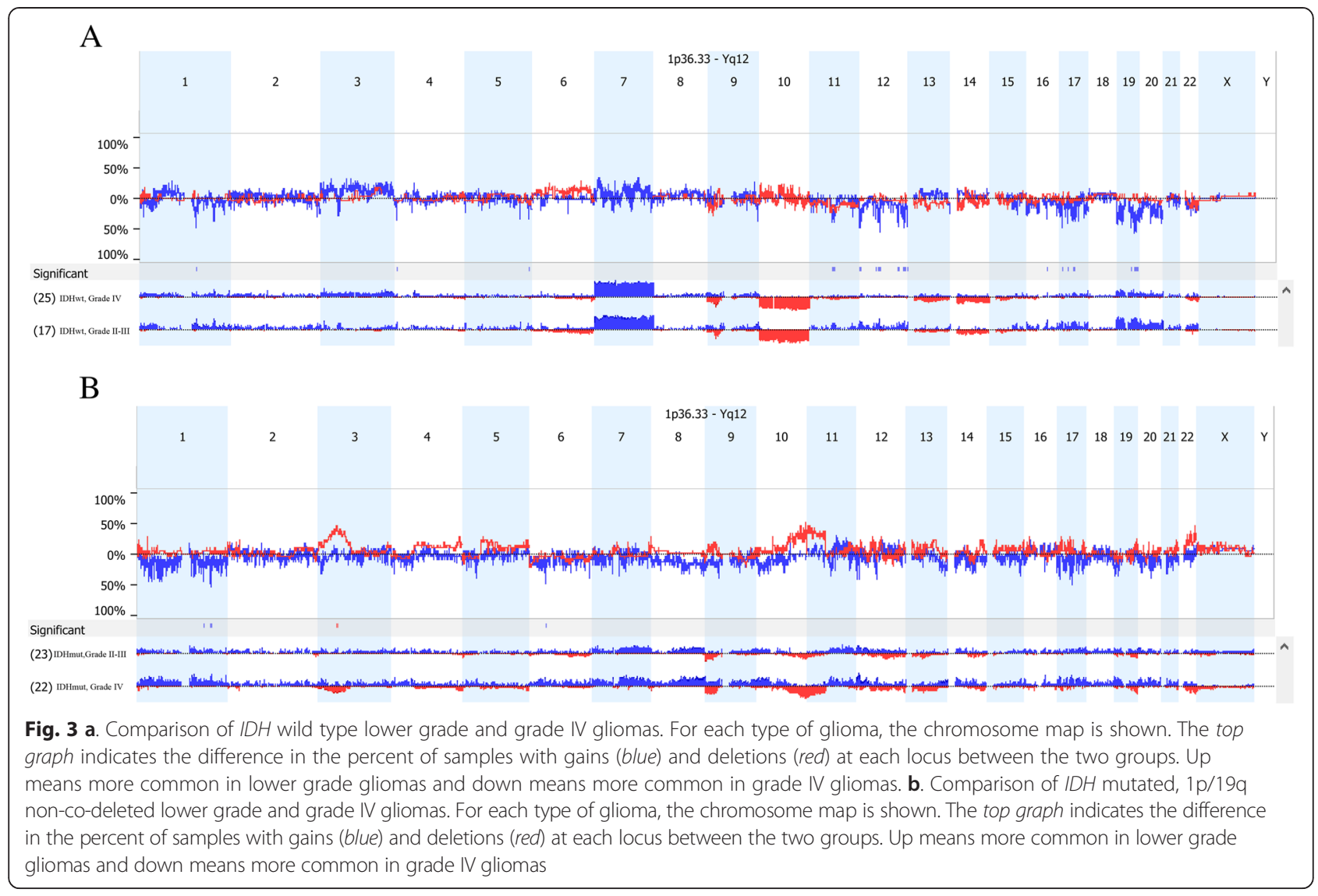

lower grade $I D H^{\text {mut }}$ gliomas. The other predominant cluster contained $35 \%(8)$ of the lower grade $I D H^{\text {mut }}$ gliomas and $12 \%$ (3) of the IDH ${ }^{\text {mut }}$ GBMs. A third smaller cluster contained one GBM and four lower grade gliomas (Fig. 2c). The most significant difference $\left(P=5 \times 10^{-5}\right)$ between the two largest clusters was loss of the terminal end of the $q$ arm of chromosome 10 including MGMT, which occurred in $80 \%$ of the cluster with most of the GBMs and $9 \%$ of the cluster with primarily lower grade gliomas (Additional file 4: Table S4). Loss of PTEN, which is more proximal on chromosome 10, was also associated with the two largest clusters, although not as tightly. Thus, it is not clear if the important gene on chromosome 10 is PTEN or MGMT or both.

Grade IV IDH ${ }^{\text {mut }}$ gliomas are considered to be secondary GBMs that have progressed from lower grade gliomas. Therefore, differences between lower grade and grade IV $I D H^{\text {mut }}$ gliomas may indicate genes or pathways that are important for progression of $\mathrm{IDH}^{\text {mut }}$ gliomas. In addition to the losses in 10q indicated above, grade IV $I D H^{\text {mut }}$ gliomas were more likely to have gains of 1q25.3 (SMG7, NCF2), 1q32.1 (KIF14, DDX59, BTG2), 6p21.1 (HSP90AB1 and other genes) and loss of 3p21 (multiple genes). A broad loss of heterozygosity $(\mathrm{LOH})$ on $11 \mathrm{p} 15$ was also more common in the grade
IV gliomas (Additional file 5: Table S5 and Fig. 3b). Applying functional gene ontology analysis to genes on these chromosome segments, the only enriched pathway was nitrogen compound transport (Additional file 6: Table S6). Both lower grade and grade IV IDH ${ }^{\text {mut }}$ gliomas were enriched foralterations in the PI3K/AKT pathway. However, only $I D H^{\text {mut }}$ grade IV gliomas were enriched for alterations in pathways involving regulation of actin cytoskeleton, RAS, and EGFR. These differences suggest that RAS signaling and cytoskeletal abnormalities may play a role in progression of $I D H^{\text {mut }}$ gliomas.

\section{Increased genomic instability is observed in $I D H^{\text {mut }}$ gliomas}

We observed a mean number of gains and losses of 150 CNA/sample (range 11-1070) in all samples. Overall, Grade IV tumors had higher CNA frequency than lower grade tumors. Unexpectedly, the highest frequency of alterations was seen in $I D H^{\text {mut }}$ grade IV gliomas. Grade IV $I D H^{\text {mut }}$ gliomas had more than double th number of CNA than any of the other three groups $(p=0.0078$ by ANOVA, with pairwise $p$-values $<0.008$ for all three pairs, Fig. 4a). Although the absolute number of chromosome abnormalities can change based on analysis threshold parameters and our analysis was designed to minimize 


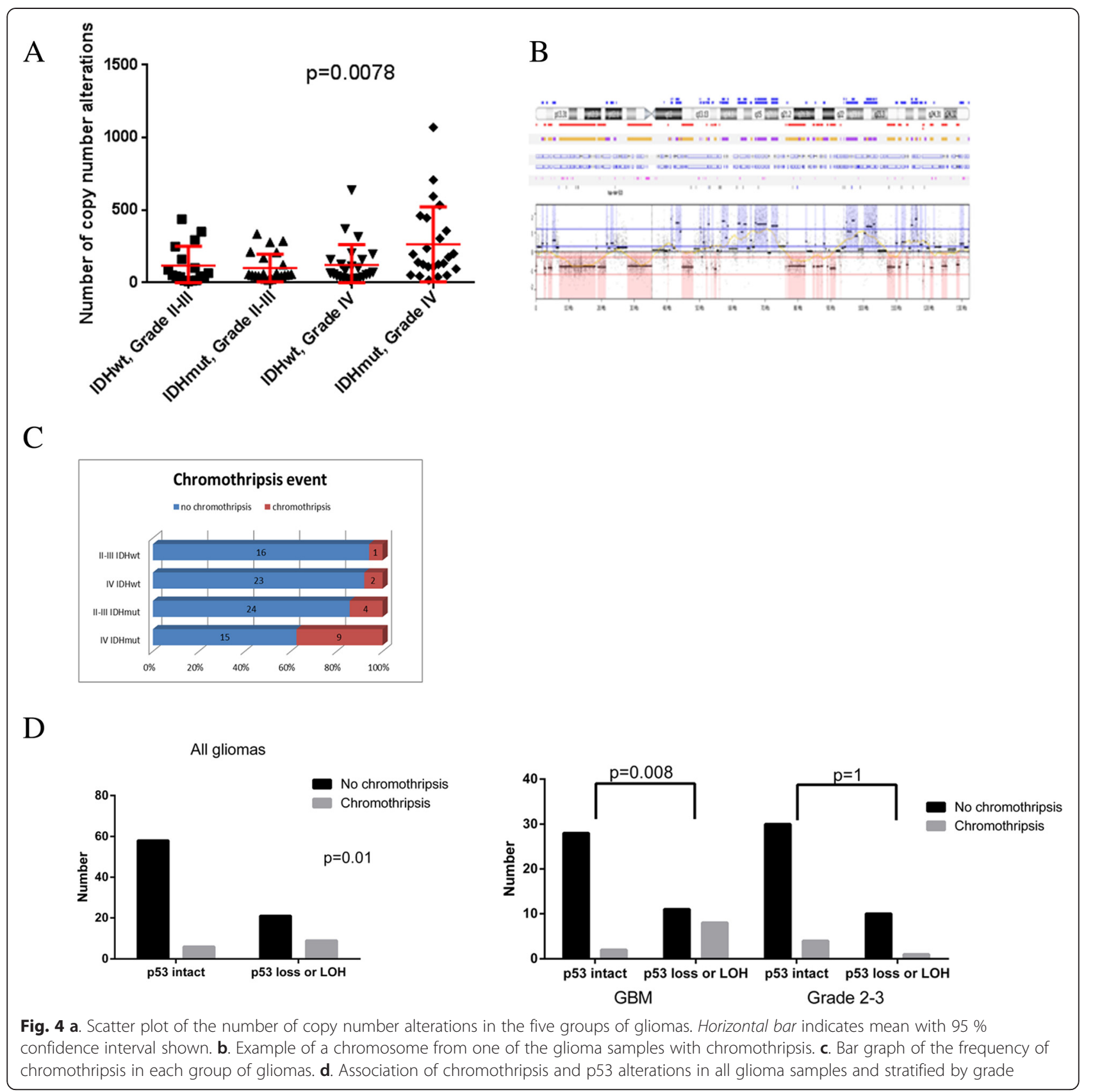

undercalling, the differences between groups were not affected by varying thresholds. These findings suggest that increasing chromosome instability is a hallmark of the progression of $I D H^{\text {mut }}$ lower grade gliomas into high grade. Whether this chromosome instability is a cause or effect of increasing grade cannot be determined from our data.

We also examined the TCGA GBM and lower grade glioma datasets for total number of copy number alterations. Significantly more copy number alterations were seen in both the $I D H^{\text {mut }}$ Grade IV (mean 132.1, median 105 per sample) and $I D H^{\mathrm{wt}}$ Grade IV (mean 132.8, median
96.5 per sample) tumors compared to the lower grade $I D H^{\text {mut }}$ (mean 63.04, median 53 per sample) and $I D H^{\text {wt }}$ (mean 53.9, median 40 per sample) gliomas. However, due to the small number of $I D H^{\text {mut }}$ GBM with copy number data (17), the power for comparing the number of CNA between $I D H^{\mathrm{mut}}$ and $I D H^{\mathrm{wt}} \mathrm{GBM}$ was low. Moreover, unlike our samples, the lower grade and grade IV samples in the TCGA were run separately, so batch effects are possible.

Given the subgroup differences in CNA frequency, we examined the specific patterns of alterations across the whole genome and looked within groups at the specific 
CNAs on chromosomes with a high number of alterations. The term chromothripsis describes situations in which there are a large number of chromosomal rearrangements over localized chromosomal regions [10, 38]. In our analysis, we used the definition of at least 10 switches between two copy-number states (gain and loss) on at least one individual chromosome for a tumor to be considered to have chromothripsis. An example of a chromosome with chromothripsis is shown in Fig. 4b. By this definition, 11 of our samples contained chromothripsis. Chromothripsis was significantly more common in $I D H^{\text {mut }}$ Grade IV tumors than $I D H^{\mathrm{wt}}(p=0.002)$ or lower grade $I D H^{\text {mut }}(p=0.05$, Fig. $4 \mathrm{c})$.

We hypothesized that loss of function of p53 would predispose to chromothripsis because of the inability of p53 deficient cells to undergo apoptosis in the face of chromosome shattering. Indeed, gliomas with chromosome loss at the TP53 locus or LOH at the TP53 locus were more likely to have chromothripsis than those with no alteration of TP53 (Fig. 4d), although this relationship was limited to Grade IV tumors.

The prognostic significance of chromothripsis is unknown. In our cohort, chromothripsis was not prognostic.

\section{Alterations in cancer associated genes reveal the biological differences between molecular subtypes}

To illustrate the similarities and differences between the four subgroups of $1 \mathrm{p} / 19 \mathrm{q}$ non-co-deleted gliomas, we examined the pattern of alterations of three well-described glioma associated genes. We used Venn diagrams to visualize patterns of CNAs in the oncogene EGFR (7p11.2) and the tumor suppressor genes CDKN2A (9p21.3) and PTEN (10q23.31) (Although our data cannot determine whether CNAs affecting these genes are functionally targeting these genes or nearby ones, these are genes with known functional significance in gliomas.). For this analysis, we only included CNAs that affected the whole gene, (6\% of samples had losses within CDKN2A or PTEN and $11 \%$ of samples had gains within EGFR that did not affect the whole gene) (Fig. 5a).

Gain of EGFR and loss of PTEN and CDKN2A occur together frequently in both $I D H^{\mathrm{wt}}$ lower grade and grade IV gliomas (all three occurring together in $53 \%$ and $40 \%$, respectively), with no significant differences of these alterations by grade. On the other hand, EGFR gain is significantly rarer overall in $I D H^{\text {mut }}$ gliomas (17 \% grade II-III, $25 \%$ grade IV) and CDKN2A loss is slightly lower (39 \% grade II-III, $42 \%$ grade IV) compared with $I D H^{\mathrm{wt}}$. Moreover, seeing all three alterations is very rare in $I D H^{\text {mut }}$ gliomas, only occurring in $4 \%$ regardless of grade. We did observe significant differences in PTEN loss associated with grade in $I D H^{\text {mut }}$ tumors $\left(17 \% I D H^{\text {mut }}\right.$ grade II-III and $46 \% I D H^{\text {mut }}$ grade IV $[p=0.025])$. These findings suggest that loss of PTEN or genes near it on chromosome 10q may be a key and unique factor associated with progression of $I D H^{\mathrm{mut}}$ tumors to grade IV.

To examine the functional significance of the chromosome alterations seen in the different groups, we examined a predetermined list of genes in pathways previously shown to be altered and functionally important in gliomas, including receptor tyrosine kinases (RTK), phosphatidylinositol-3-kinase, NF-kB, P53, and cell cycle regulators (Fig. 5b). These genes were considered altered if they were in an extended region identified by GISTIC analysis as having a $q$-value $<0.25$. Although most gliomas show alterations in all of these pathways, the mechanism by which the pathways are altered can differ. $I D H^{\mathrm{wt}}$ gliomas had significantly more chromosome alterations affecting RTK signaling than $I D H^{\text {mut }}$ gliomas. PI3K pathway activation also differed based on $I D H$ status: upstream changes such as PTEN deletion or $A K T$ gain were more common in $I D H^{\mathrm{wt}}$ gliomas and MTOR gain was significantly less common $\left(p=2 \times 10^{-7}, 0.002\right.$, and $1 \times 10^{-5}$, respectively). Such differences could have implications for application of multiple targeted treatments to these glioma subtypes. Among cell cycle regulators, $I D H^{\mathrm{wt}}$ gliomas were significantly more likely to have CDK1 loss and less likely to have cyclin A1 gene loss or cyclin D1 or E2 gene gain.

\section{Prognostic factors}

The strongest prognostic factors in the whole population were $I D H$ status and grade (Fig. 1c). In multivariate analysis, the other significant variables were loss of the estrogen receptor B (ESR2), gain of CDKN1C, and TP53 loss, each of which was a negative prognostic factor (Additional file 7: Table S7). Given the biologic and clinical differences between the four subgroups defined by $I D H$ status and grade, we sought to identify distinct prognostic factors within each subgroup and within the entire $I D H^{\text {mut }}$ and $I D H^{w t}$ groups. Although univariate analysis identified distinct copy number alterations in each subgroup that were significantly associated with survival in our cohort, none were significantly associated with survival when we attempted to validate them using 433 GBM and 181 lower grade glioma samples from the TCGA obtained via Nexus premier.

\section{Discussion}

We present one of the first comparative analyses of CNAs among glioma subgroups defined by WHO grade and $I D H$ mutation status. Confirming prior observations, we observe significant chromosomal differences between $I D H$-mutant and $I D H$-wild type tumors. When analyzing subgroups by grade and mutation status, we find few significant copy number differences between $I D H^{\mathrm{wt}}$ lower grade and $I D H^{\mathrm{wt}}$ grade IV gliomas. These genomic similarities support the concept that despite their histologic 


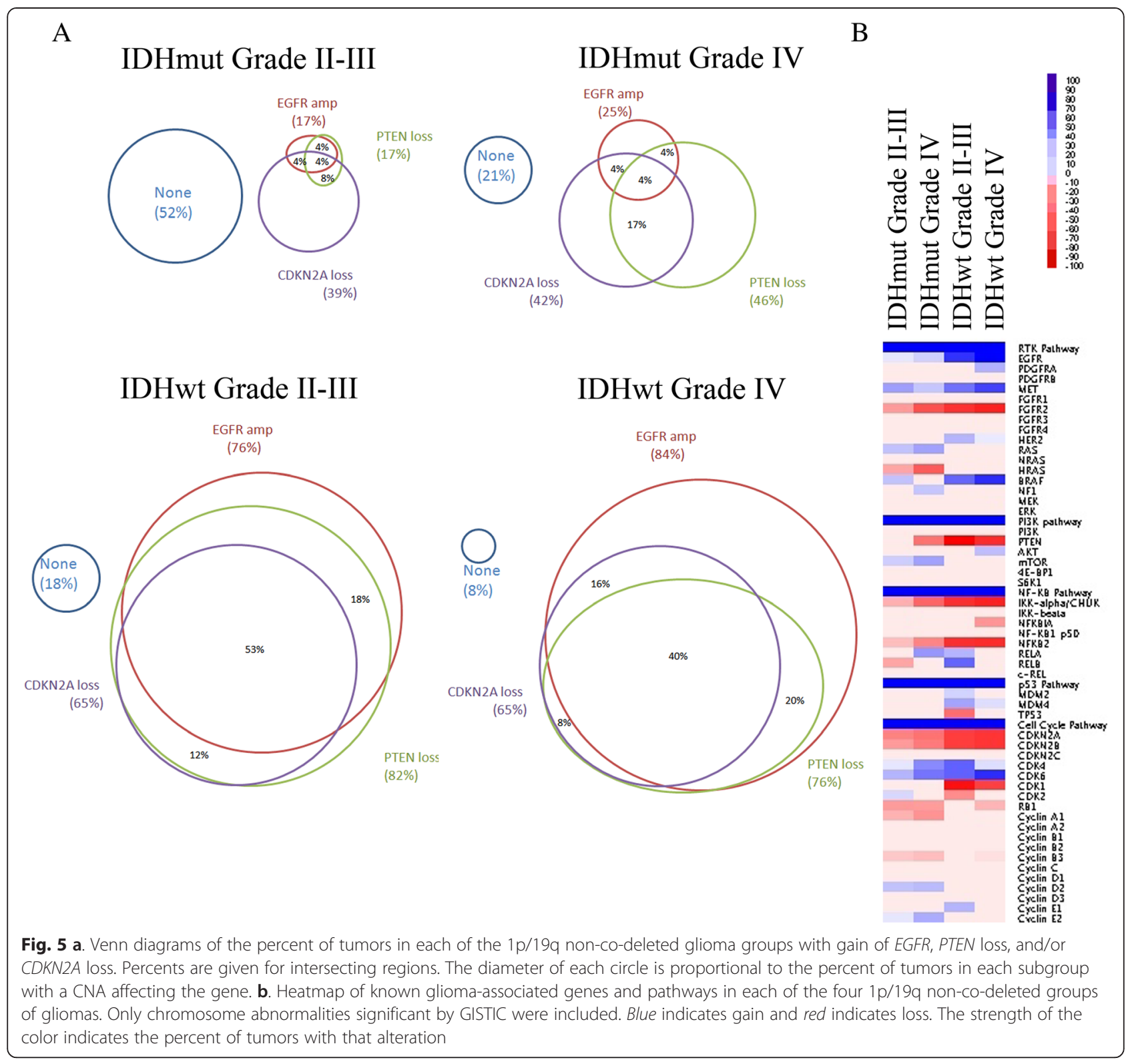

appearance, biologically these lower grade $I D H^{\mathrm{wt}}$ tumors are pre-glioblastomas with a median survival a mere 7 months longer than grade IV gliomas, with few long-term survivors [24]. In contrast, among $I D H^{\text {mut }}$ tumors, clustering based on copy number demonstrates that lower grade and grade IV gliomas with IDH mutations are distinct biologic entities; they also have distinct prognosis. The progression of $I D H^{\text {mut }}$ gliomas from lower grade to grade IV involves multiple CNAs, particularly on chromosome 10q, affecting biologically relevant pathways including: activation of PI3K signaling through loss of PTEN and gain of mTOR, as well as activation of cell cycle signaling through gain of CDK4, CDK6, and cyclinE2. MGMT loss may play a role as well, consistent with the resistance of MGMT unmethylated ${ }^{\mathrm{t}}$ gliomas to alkylating agents.
In comparison to $I D H^{m u t}$ gliomas, $I D H^{\mathrm{wt}}$ gliomas have greater activation of receptor tyrosine kinase signaling through EGFR gain, $M E T$ gain, and BRAF gain, in addition to increased gains in cell cycle activators and losses of cell cycle inhibitors compared to $I D H^{\text {mut }}$ gliomas. This is likely to be biologically relevant, as others have shown that the number of CNAs in the receptor tyrosine kinase pathway correlates with pathway activation measured by downstream kinase phosphorylation [16]. Amplification of EGFR has been shown to separate GBM into distinct clusters $[8,26,2]$. Although $I D H$ mutation status was not reported in these clustering papers, alterations seen in the non-EGFR amplified group, such as losses on chromosome 13, mirror those seen in our $I D H^{\text {mut }}$ glioblastomas. The lack of EGFR amplification in 
$I D H^{\text {mut }}$ glioblastoma was also seen in the TCGA samples [4]. A similar pattern of chromosome gains and losses distinguished primary and secondary glioblastoma, which have a high rate of $I D H$ mutations [22]. These results validate our findings that growth factor receptor signaling, particularly in the EGFR pathway, differs between $I D H^{\text {mut }}$ and $I D H^{\mathrm{wt}}$ gliomas.

We found an unexpectedly large number of intrachromosomal breakpoints, also known as chromothripsis, in our $I D H^{\text {mut }}$ GBM tumors. Upon closer inspection, we observed that chromothripsis is more likely when TP53 is altered through deletion and/or $\mathrm{LOH}$, and others have found that astrocytes lacking p53 have more chromosome breaks [47] and medulloblastoma due to inherited TP53 mutations have increased chromothripsis [32]. Different definitions of chromothripsis have been proposed in the literature, and although many of our samples meet the common definition of chromothripsis, they do not all fit into every definition of chromothripsis $[38,19]$. Therefore, we cannot conclude whether the massive intrachromosomal instability seen in $I D H^{\text {mut }}$ gliomas in our samples occurs in one event ("true" chromothripsis) or in sequential events over time (severe chromosomal instability). Nevertheless, our data support that $I D H^{\text {mut }}$ high grade tumors contain the highest number of alternating, intrachromosomal breakpoints.

Our study strengths include the relatively large number of $I D H^{\mathrm{mut}} \mathrm{GBM}$ and $I D H^{\mathrm{wt}}$ lower grade gliomas relative to other data sets (including TCGA), allowing us to better characterize these uncommon groups. In addition, we have been able to use relatively novel, highresolution MIP technology to analyze archived FFPE tissue with associated clinical variables and mature outcome data. Weaknesses include the overall small size of the series, which means that conclusions, particularly about between group differences and within group prognostic factors, must be taken as hypothesis-generating.

\section{Conclusions}

In conclusion, we have shown that $I D H$ and grade define four distinct groups of 1p/19q non-co-deleted gliomas determined by functionally important CNAs and unique prognostic factors. $I D H^{\mathrm{wt}}$ lower grade gliomas and grade IV gliomas are closely related and driven by common and well known alterations including EGFR amplification and PTEN deletion, while $I D H^{\text {mut }}$ lower grade gliomas remain functionally distinct from grade IV gliomas. The transition of $I D H^{\text {mut }}$ lower grade gliomas to grade IV gliomas involves loss of PTEN and dysregulation of cell cycle regulators, in addition to an apparent higher frequency of chromosomal instability and/or chromothripsis.

\section{Additional files}

Additional file 1: Table S1. Loci with copy number alterations with an
FDR $<0.25$ using the GISTIC algorithm in (A) IDH' $H^{\text {mut }} G B M,(B) I D H^{\text {mut }}$
Grade II-III gliomas, (C) IDH $H^{\text {wt }} G B M$, and (D) IDH $H^{\text {wt }}$ Grade II-III gliomas.
Columns give the percent of samples within each subgroup with allelic
imbalance, low level copy number gain, low level copy number loss, high
level copy number gain, and homozygoud deletion at each locus.

Additional file 2: Table S2. Loci with copy number alterations that are significantly different between $I D H^{\text {mut }}$ and $I D H^{\text {wt }}$ gliomas, regardless of grade, with FDR $<0.25$.

Additional file 3: Table S3. Loci with copy number alterations that are significantly different between low and high grade $I D H^{\text {wt }}$ gliomas with FDR $<0.25$

Additional file 4: Table S4. Loci with copy number alterations that are significantly different between the two clusters of $I D H^{\text {mut }}$ gliomas identified by hierarchical clustering with FDR $<0.25$.

Additional file 5: Table S5. Loci with copy number alterations that are significantly different between low and high grade $I D H^{\text {mut }}$ gliomas with FDR $<0.25$.

Additional file 6: Table S6. Gene Ontology categories and pathways enriched using the ToppGene algorithm for (A) IDH' ${ }^{\text {mut }}$ Grade II-III gliomas, (B) IDH $H^{\text {mut }} \mathrm{GBM}$, (C) IDH $H^{\mathrm{wt}}$ Grade II-III gliomas, (D) IDH $H^{\mathrm{wt}} \mathrm{GBM}$, (E) differences between $I D H^{\text {mut }}$ lower grade and high grade gliomas, and ( $F$ ) differences between $I D H^{\text {wt }}$ low and high grade gliomas.

Additional file 7: Table S7. Univariate and multivariate survival analysis in the entire population and within the four subgroups of $1 p / 19 q$ non-co-deleted gliomas.

\section{Competing interests}

The authors declare that they have no competing interests.

\section{Author's contributions}

ALC performed copy number analyses, survival analyses, and drafted the manuscript. MS performed copy number analyses, analysis of chromothripsis, and drafted the manuscript. KA performed pathologic analysis and provided samples. KA-M and LH provided sample preparation and data. STS performed copy number analysis. LMA performed the MIP assays. JDS analyzed copy number data, supervised MIP assays, and drafted the manuscript. $\mathrm{HC}$ provided samples and sample data, performed copy number analysis, and drafted the manuscript. All authors read and approved the final manuscript.

\section{Author's information}

Howard Colman and Joshua D. Schiffman share equal senior authorship for this work.

Adam L. Cohen and Mariko Sato are equal first authors.

\section{Acknowledgement}

This research was funded in part by a grant from the National Institutes of Health/National Cancer Institute (5P50 CA127001) to H.C. and K.A. and by the Huntsman Cancer Foundation (to H.C.). We acknowledge Dr. Soheil Shams and BioDiscovery, Inc. for their assistance in analyzing the genomic copy number data. J.D.S. holds the Edward B. Clark, MD Chair in Pediatric Research, and J.D.S. and C.C.M. are supported through the Primary Children's Hospital (PCH) Pediatric Cancer Program, funded by the Intermountain Healthcare Foundation and the Primary Children's Hospital Foundation. A.L.C. acknowledges the inspiration of Jessica Jennifer Cohen. None of the authors has a competing financial interest.

\section{Author details}

${ }^{1}$ Huntsman Cancer Institute, University of Utah, 2000 Circle of Hope, Salt Lake City, UT 84112, USA. ${ }^{2}$ Children's Hospital, University of lowa, 200 Hawkins Dr, 2524 JCP, lowa City, IA 52242, USA. ³Department of Pathology, MD Anderson Cancer Center, Houston, TX 77030, USA. ${ }^{4}$ ARUP Laboratories, Salt Lake City, UT 84112, USA. ${ }^{5}$ Department of Pediatrics, University of Utah, Salt Lake City, UT 84112, USA. 'Department of Pathology, University of Utah, Salt Lake City, UT 84112, USA. 
Received: 12 May 2015 Accepted: 13 May 2015

Published online: 20 June 2015

\section{References}

1. Benjamini YHY (1995) Controlling the false discovery rate: a practical and poweful approach to multiple testing. Journal of the Royal Statistical Society Series B (Methodological) 57:289-300

2. Bredel M, Bredel C, Juric D, Harsh GR, Vogel H, Recht LD, Sikic BI (2005) High-resolution genome-wide mapping of genetic alterations in human glial brain tumors. Cancer research 65:4088-4096. doi:10.1158/00085472.CAN-04-4229

3. Brennan C, Momota H, Hambardzumyan D, Ozawa T, Tandon A, Pedraza A, Holland E (2009) Glioblastoma subclasses can be defined by activity among signal transduction pathways and associated genomic alterations. PloS one 4, e7752. doi:10.1371/journal.pone.0007752

4. Brennan CW, Verhaak RG, McKenna A, Campos B, Noushmehr H, Salama SR, Zheng S, Chakravarty D, Sanborn JZ, Berman SH, Beroukhim R, Bernard B, Wu CJ, Genovese G, Shmulevich I, Barnholtz-Sloan J, Zou L, Vegesna R, Shukla SA, Ciriello G, Yung WK, Zhang W, Sougnez C, Mikkelsen T, Aldape K, Bigner DD, Van Meir EG, Prados M, Sloan A, Black KL et al (2013) The somatic genomic landscape of glioblastoma. Cell 155:462-477. doi:10.1016/j.cell.2013.09.034

5. Chen J, Bardes EE, Aronow BJ, Jegga AG (2009) ToppGene Suite for gene list enrichment analysis and candidate gene prioritization. Nucleic acids research 37:W305-W311. doi:10.1093/nar/gkp427

6. Crespo I, Vital AL, Nieto AB, Rebelo $O$, Tao H, Lopes MC, Oliveira CR, French PJ, Orfao A, Tabernero MD (2011) Detailed characterization of alterations of chromosomes 7, 9, and 10 in glioblastomas as assessed by singlenucleotide polymorphism arrays. The Journal of molecular diagnostics : JMD 13:634-647. doi:10.1016/j.jmoldx.2011.06.003

7. Dahlback HS, Gorunova L, Brandal P, Scheie D, Helseth E, Meling TR, Heim S (2011) Genomic aberrations in diffuse low-grade gliomas. Genes, chromosomes \& cancer 50:409-420. doi:10.1002/gcc.20866

8. de Tayrac M, Etcheverry A, Aubry M, Saikali S, Hamlat A, Quillien V, Le Treut A, Galibert MD, Mosser J (2009) Integrative genome-wide analysis reveals a robust genomic glioblastoma signature associated with copy number driving changes in gene expression. Genes, chromosomes \& cancer 48:55-68. doi:10.1002/gcc.20618

9. Dolecek T, Propp J, Stroup N, Kruchko C (2012) CBTRUS statistical report: primary brain and central nervous system tumors diagnosed in the United States in 2005-2009. Neuro-oncology 15:v1-v49

10. Forment JV, Kaidi A, Jackson SP (2012) Chromothripsis and cancer: causes and consequences of chromosome shattering. Nature reviews Cancer 12:663-670

11. Gorovets D, Kannan K, Shen R, Kastenhuber ER, Islamdoust N, Campos C, Pentsova E, Heguy A, Jhanwar SC, Mellinghoff IK, Chan TA, Huse JT (2012) IDH mutation and neuroglial developmental features define clinically distinct subclasses of lower grade diffuse astrocytic glioma. Clinical cancer research : an official journal of the American Association for Cancer Research 18:2490-2501. doi:10.1158/1078-0432.CCR-11-2977

12. Hirose $Y$, Aldape KD, Chang S, Lamborn K, Berger MS, Feuerstein BG (2003) Grade II astrocytomas are subgrouped by chromosome aberrations. Cancer genetics and cytogenetics 142:1-7

13. Hobbs J, Nikiforova MN, Fardo DW, Bortoluzzi S, Cieply K, Hamilton RL, Horbinski C (2012) Paradoxical relationship between the degree of EGFR amplification and outcome in glioblastomas. The American journal of surgical pathology 36:1186-1193. doi:10.1097/PAS.0b013e3182518e12

14. Huncharek M, Kupelnick B (2000) Epidermal growth factor receptor gene amplification as a prognostic marker in glioblastoma multiforme: results of a meta-analysis. Oncology research 12:107-112

15. Hurtt MR, Moossy J, Donovan-Peluso M, Locker J (1992) Amplification of epidermal growth factor receptor gene in gliomas: histopathology and prognosis. Journal of neuropathology and experimental neurology 51:84-90

16. Jeuken J, van den Broecke C, Gijsen S, Boots-Sprenger S, Wesseling P (2007) RAS/RAF pathway activation in gliomas: the result of copy number gains rather than activating mutations. Acta neuropathologica 114:121-133. doi:10.1007/s00401-007-0239-0

17. Johnson DR, Leeper HE, Uhm JH (2013) Glioblastoma survival in the United States improved after Food and Drug Administration approval of bevacizumab: a population-based analysis. Cancer. doi:10.1002/cncr.28259
18. Kim TM, Xi R, Luquette L, Park RW, Johnson MD, Park PJ (2013) Functional genomic analysis of chromosomal aberrations in a compendium of 8000 cancer genomes. Genome research 23:217-227. doi:10.1101/gr.140301.112

19. Korbel JO, Campbell PJ (2013) Criteria for inference of chromothripsis in cancer genomes. Cell 152:1226-1236. doi:10.1016/j.cell.2013.02.023

20. Lai A, Kharbanda S, Pope WB, Tran A, Solis OE, Peale F, Forrest WF, Pujara K Carrillo JA, Pandita A, Ellingson BM, Bowers CW, Soriano RH, Schmidt NO, Mohan S, Yong WH, Seshagiri S, Modrusan Z, Jiang Z, Aldape KD, Mischel PS, Liau LM, Escovedo CJ, Chen W, Nghiemphu PL, James CD, Prados MD, Westphal M, Lamszus K, Cloughesy T et al (2011) Evidence for sequenced molecular evolution of IDH1 mutant glioblastoma from a distinct cell of origin. Journal of clinical oncology : official journal of the American Society of Clinical Oncology 29:4482-4490. doi:10.1200/JCO.2010.33.8715

21. Loeper S, Romeike BF, Heckmann N, Jung V, Henn W, Feiden W, Zang KD, Urbschat S (2001) Frequent mitotic errors in tumor cells of genetically micro-heterogeneous glioblastomas. Cytogenetics and cell genetics 94:1-8

22. Maher EA, Brennan C, Wen PY, Durso L, Ligon KL, Richardson A, Khatry D, Feng B, Sinha R, Louis DN, Quackenbush J, Black PM, Chin L, DePinho RA (2006) Marked genomic differences characterize primary and secondary glioblastoma subtypes and identify two distinct molecular and clinical secondary glioblastoma entities. Cancer research 66:11502-11513. doi:10.1158/0008-5472.CAN-06-2072

23. Malhotra A, Lindberg M, Faust GG, Leibowitz ML, Clark RA, Layer RM, Quinlan AR, Hall IM (2013) Breakpoint profiling of 64 cancer genomes reveals numerous complex rearrangements spawned by homologyindependent mechanisms. Genome research 23:762-776. doi:10.1101/ gr.143677.112

24. Metellus P, Coulibaly B, Colin C, de Paula AM, Vasiljevic A, Taieb D, Barlier A, Boisselier B, Mokhtari K, Wang XW, Loundou A, Chapon F, Pineau S, Ouafik L, Chinot O, Figarella-Branger D (2010) Absence of IDH mutation identifies a novel radiologic and molecular subtype of WHO grade II gliomas with dismal prognosis. Acta neuropathologica 120:719-729. doi:10.1007/ s00401-010-0777-8

25. Misra A, Pellarin M, Nigro J, Smirnov I, Moore D, Lamborn KR, Pinkel D, Albertson DG, Feuerstein BG (2005) Array comparative genomic hybridization identifies genetic subgroups in grade 4 human astrocytoma. Clinical cancer research : an official journal of the American Association for Cancer Research 11:2907-2918. doi:10.1158/1078-0432.CCR-04-0708

26. Nigro JM, Misra A, Zhang L, Smirnov I, Colman H, Griffin C, Ozburn N, Chen M, Pan E, Koul D, Yung WK, Feuerstein BG, Aldape KD (2005) Integrated array-comparative genomic hybridization and expression array profiles identify clinically relevant molecular subtypes of glioblastoma. Cancer Res 65:1678-1686. doi:10.1158/0008-5472.CAN-04-2921

27. Noushmehr H, Weisenberger DJ, Diefes K, Phillips HS, Pujara K, Berman BP, Pan F, Pelloski CE, Sulman EP, Bhat KP, Verhaak RG, Hoadley KA, Hayes DN, Perou CM, Schmidt HK, Ding L, Wilson RK, Van Den Berg D, Shen H, Bengtsson H, Neuvial P, Cope LM, Buckley J, Herman JG, Baylin SB, Laird PW, Aldape K (2010) Identification of a CpG island methylator phenotype that defines a distinct subgroup of glioma. Cancer cell 17:510-522. doi:10.1016/j.ccr.2010.03.017

28. Ohgaki H, Dessen P, Jourde B, Horstmann S, Nishikawa T, Di Patre PL, Burkhard C, Schuler D, Probst-Hensch NM, Maiorka PC, Baeza N, Pisani P, Yonekawa Y, Yasargil MG, Lutolf UM, Kleihues P (2004) Genetic pathways to glioblastoma: a population-based study. Cancer research 64:6892-6899. doi:10.1158/0008-5472.CAN-04-1337

29. Olshen AB, Venkatraman ES, Lucito R, Wigler M (2004) Circular binary segmentation for the analysis of array-based DNA copy number data. Biostatistics 5:557-572. doi:10.1093/biostatistics/kxh008

30. Phillips HS, Kharbanda S, Chen R, Forrest WF, Soriano RH, Wu TD, Misra A, Nigro JM, Colman H, Soroceanu L, Williams PM, Modrusan Z, Feuerstein BG, Aldape K (2006) Molecular subclasses of high-grade glioma predict prognosis, delineate a pattern of disease progression, and resemble stages in neurogenesis. Cancer cell 9:157-173. doi:10.1016/j.ccr.2006.02.019

31. Rao SK, Edwards J, Joshi AD, Siu IM, Riggins GJ (2010) A survey of glioblastoma genomic amplifications and deletions. Journal of neurooncology 96:169-179. doi:10.1007/s11060-009-9959-4

32. Rausch T, Jones DT, Zapatka M, Stutz AM, Zichner T, Weischenfeldt J, Jager N, Remke M, Shih D, Northcott PA, Pfaff E, Tica J, Wang Q, Massimi L, Witt H, Bender S, Pleier S, Cin H, Hawkins C, Beck C, von Deimling A, Hans V, Brors B, Eils R, Scheurlen W, Blake J, Benes V, Kulozik AE, Witt O, Martin D et al (2012) Genome sequencing of pediatric medulloblastoma links catastrophic DNA rearrangements with TP53 mutations. Cell 148:59-71. doi:10.1016/j.cell.2011.12.013 
33. Reich M, Liefeld T, Gould J, Lerner J, Tamayo P, Mesirov JP (2006) GenePattern 2.0. Nature genetics 38:500-501. doi:10.1038/ng0506-500

34. Scherer HJ (1940) A critical review: the pathology of cerebral gliomas. J Neurol Psychiatry 3:147-177

35. Schiffman JD, Wang Y, McPherson LA, Welch K, Zhang N, Davis R, Lacayo NJ, Dahl GV, Faham M, Ford JM, Ji HP (2009) Molecular inversion probes reveal patterns of 9p21 deletion and copy number aberrations in childhood leukemia. Cancer genetics and cytogenetics 193:9-18. doi:10.1016/ j.cancergencyto.2009.03.005

36. Shapiro JR, Yung WK, Shapiro WR (1981) Isolation, karyotype, and clonal growth of heterogeneous subpopulations of human malignant gliomas. Cancer research 41:2349-2359

37. Shibahara I, Sonoda Y, Kanamori M, Saito R, Yamashita Y, Kumabe T, Watanabe M, Suzuki H, Kato S, Ishioka C, Tominaga T (2012) IDH1/2 gene status defines the prognosis and molecular profiles in patients with grade III gliomas. International journal of clinical oncology 17:551-561. doi:10.1007/ s10147-011-0323-2

38. Stephens PJ, Greenman CD, Fu B, Yang F, Bignell GR, Mudie LJ, Pleasance ED, Lau KW, Beare D, Stebbings LA, McLaren S, Lin ML, McBride DJ, Varela I, Nik-Zainal S, Leroy C, Jia M, Menzies A, Butler AP, Teague JW, Quail MA, Burton J, Swerdlow H, Carter NP, Morsberger LA, lacobuzio-Donahue C, Follows GA, Green AR, Flanagan AM, Stratton MR et al (2011) Massive genomic rearrangement acquired in a single catastrophic event during cancer development. Cell 144:27-40. doi:10.1016/j.cell.2010.11.055

39. Storey JD, Tibshirani R (2003) Statistical methods for identifying differentially expressed genes in DNA microarrays. Methods Mol Biol 224:149-157

40. Storey JD, Tibshirani R (2003) Statistical significance for genomewide studies. Proc Natl Acad Sci U S A 100:9440-9445. doi:10.1073/ pnas. 1530509100

41. Sturm D, Witt $H$, Hovestadt $V$, Khuong-Quang DA, Jones DT, Konermann C, Pfaff E, Tonjes M, Sill M, Bender S, Kool M, Zapatka M, Becker N, Zucknick M, Hielscher T, Liu XY, Fontebasso AM, Ryzhova M, Albrecht S, Jacob K, Wolter M, Ebinger M, Schuhmann MU, van Meter T, Fruhwald MC, Hauch H, Pekrun A, Radlwimmer B, Niehues T, von Komorowski G et al (2012) Hotspot mutations in $\mathrm{H} 3 \mathrm{~F} 3 \mathrm{~A}$ and IDH1 define distinct epigenetic and biological subgroups of glioblastoma. Cancer cell 22:425-437. doi:10.1016/ j.ccr.2012.08.024

42. van den Bent MJ, Hartmann C, Preusser M, Strobel T, Dubbink HJ, Kros JM, von Deimling A, Boisselier B, Sanson M, Halling KC, Diefes KL, Aldape K, Giannini C (2013) Interlaboratory comparison of IDH mutation detection. Journal of neuro-oncology 112:173-178. doi:10.1007/s11060-013-1056-Z

43. Verhaak RG, Hoadley KA, Purdom E, Wang V, Qi Y, Wilkerson MD, Miller CR, Ding L, Golub T, Mesirov JP, Alexe G, Lawrence M, O'Kelly M, Tamayo P, Weir BA, Gabriel S, Winckler W, Gupta S, Jakkula L, Feiler HS, Hodgson JG, James CD, Sarkaria JN, Brennan C, Kahn A, Spellman PT, Wilson RK, Speed TP, Gray JW, Meyerson M et al (2010) Integrated genomic analysis identifies clinically relevant subtypes of glioblastoma characterized by abnormalities in PDGFRA, IDH1, EGFR, and NF1. Cancer cell 17:98-110. doi:10.1016/ j.ccr.2009.12.020

44. Wang Y, Cottman M, Schiffman JD (2012) Molecular inversion probes: a novel microarray technology and its application in cancer research. Cancer genetics 205:341-355. doi:10.1016/j.cancergen.2012.06.005

45. Wang Y, Moorhead M, Karlin-Neumann G, Falkowski M, Chen C, Siddiqui F, Davis RW, Willis TD, Faham M (2005) Allele quantification using molecular inversion probes (MIP). Nucleic acids research 33, e183. doi:10.1093/nar/ gni177

46. Wiltshire RN, Herndon JE II, Lloyd A, Friedman HS, Bigner DD, Bigner SH, McLendon RE (2004) Comparative genomic hybridization analysis of astrocytomas: prognostic and diagnostic implications. J Mol Diagn 6:166-179. doi:10.1016/S1525-1578(10)60507-7

47. Yahanda AM, Bruner JM, Donehower LA, Morrison RS (1995) Astrocytes derived from p53-deficient mice provide a multistep in vitro model for development of malignant gliomas. Molecular and cellular biology 15:4249-4259

48. Yan H, Parsons DW, Jin G, McLendon R, Rasheed BA, Yuan W, Kos I, BatinicHaberle I, Jones S, Riggins GJ, Friedman H, Friedman A, Reardon D, Herndon J, Kinzler KW, Velculescu VE, Vogelstein B, Bigner DD (2009) IDH1 and IDH2 mutations in gliomas. The New England journal of medicine 360:765-773. doi:10.1056/NEJMoa0808710

\section{Submit your next manuscript to BioMed Central and take full advantage of:}

- Convenient online submission

- Thorough peer review

- No space constraints or color figure charges

- Immediate publication on acceptance

- Inclusion in PubMed, CAS, Scopus and Google Scholar

- Research which is freely available for redistribution

Submit your manuscript at www.biomedcentral.com/submit 